\title{
As I Unnecessarily Lost my Left Hip in Dg. the Femoral Head Necrosis
}

\author{
Antonín Cuc* \\ The International Expert in Occupational Health and Safety, Czech Technical University, Europe \\ *Corresponding author: Antonín Cuc, The International Expert in Occupational Health and Safety, Czech Technical University, Na Míćánkách \\ 435/1,101 00 Prague 10, Czech Republic, Europe, Email: betruea@gmail.com
}

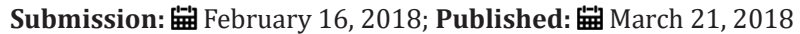

\section{Editorial}

At the beginning of 2004, I was 59 years old, I was poorly trained with a new Surface Sleighsweep in the snow - I dropped from the height of my buttock where there was a big blood swelling about 7 centimeters in diameter. The pains did not lose even after a few months, it had only solid edges. After a few months, my left hip began to collapse, sometimes I was completely eliminated for a few minutes from locomotion, then it managed to overcome the light massage and another attack of pain inside my hip was repeated until the next day. As an inquisitive patient, I lectured at the Prague Municipal Library to study the Orthopedic Medical Encyclopaedia, where I personally suspected that it might be Necrosis of the left femoral head, according to the typical symptoms of the patient's troubles. So I went to the ambulance of my practical Mrs. MDr Physician and I asked her to provide me with a request for X-ray examination of the hip at the Orthopedic Clinic of the Faculty Hospital Královské Vinohrady in Prague 10. The X-ray analyst carefully listened to me and looked at the X-ray image from the beginning of September 2004, there are no obvious destructive changes on the X-ray of the hip, but that does not mean that my patient's situation is very serious. She did not ask me to bring a new order for the Distant Magnetic Resonance to detect the initial phase of Femoral Necrosis, but she sent me for further examination at the Neurology Clinic of the same hospital. The Prime Dr.of Neurology, me igned carefully scratched the hip and skeletal functions, but he did not send me again to the desired differential diagnosis of femoral head necrosis using MRI-because he was mistakenly assumed-that it was the cause of spinal nerve ending - with casual both - hip and back pains. Procedure Neurology was not expertly wrong but ignored my initial suspicion about of Necrosis of left femoral head. The neurologist has decided Treatment - that the painful state should bridle local anesthesia with a syringe inserted directly at the end of the spine - in the hope that painful inflammation in the spine, as well as the left hips will calm down and the hip joint will functionally revitalize again. The origin premise of neurologist was wrong for allways worse Patient Health status in duratiion of 4 weeks,. There was a clear mistake that Neuorolog kept on his primary hypothesis about Diagnosis, but my patient hypothesis did not at least do the additional differential diagnosis with MRI, my patient council did not take seriously. It is for these reasons that during the tragic 4 weeks the surface sliding surface of the hip joint was completely destroyed. On the next X-ray image at the beginning of November 2004, the revitalization of the joint function was completely impossible without at least a shorter surgical orthopedic procedure. According to the Orthopedic Encyclopedia, the first stages of the development of necrosis of the femoral head are easily naturally revitalized-only the basic limitations of locomotion with bedtime and the use of revitalizing dietary and medical supplements, with hip autosomes and controlling effects by MRI after 5 weeks. In my private case of orthopedic and already significant damage of the hip joint, the application of Total endoprosthesis is possible only in the highest stage of the 5th stage, but the Orthopedic Clinic of the Faculty Hospital Královské Vinohrady, Prague 10 CZ, offered me the term of Surgeon THA till in May 2005, when I could not walk from the place. That made me look for an next Orthopedic Promotion at the Regional Regional Hospital Mladá Boleslav where I was implanted with an artificial joint Bicontact $\mathrm{S}$, noncemented, already on January 4, 2005. The operation of the hip TEP was performed properly and functionally, but unnecessarily about 5 years earlier before it was for me Patient-friendly - because none of the Orthopedists, Radiologists and Healers - could not use the recommended advanced diagnostic and therapeutic procedures for the diagnosis of femoral head necrosis by Orthopedic Encyklopedia -nor on the scale and knowledges of a typical orthopedic educated patient with a right defined probable Dg. According to a sample of about random choice about 50 cases Patient Cluster with the femoral Head with Necrosis in a likehood Orthopadic Clinic... it can be seen with statistic evidency todays trends: -that Orthopadic Clinics, Orthopedists and Radiologists always prefer large surgical orthopadic procedures -on which the Orthopedic Clinic and Hospitals can sneeze, including doctors, while the interests and preferency of the orthopedic patients are else - after the perfect lifestyle till ages 90+, with locomotive and personal mental high private safety conditions - allways with consistently prevency and 
eliminating the needless Patient risks, eliminate needless use of local and general anesthesia by preliminary THA including, in no case there are a independent supervisions of the Health Assurances, or the Providers of health services in orthopedics in hospital nets oecd - best reliable decidinig and sharing best medical experiences in principles Based Evidenced Medicine not warrant! The Profits of Providers Health care are priorities. (c) (- Creative Commons Attribution 4.0

For possible submissions Click Here

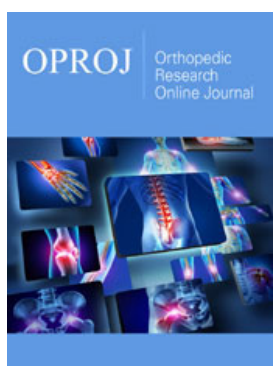

Orthopedic Research Online Journal

\section{Benefits of Publishing with us}

- High-level peer review and editorial services

- Freely accessible online immediately upon publication

- Authors retain the copyright to their work

- Licensing it under a Creative Commons license

- Visibility through different online platforms 